\title{
Explorando a Rede Social Educacional no ensino de línguas: possibilidades, gêneros e multiletramentos.
}

\author{
Susana Cristina Reis (DLEM/UFSM, suzireis@cead.ufsm.br) \\ Adilson Fernandes Gomes (PPGTER/UFSM, adilson.fernandesgomes@gmail.com) \\ Rosangela Segala de Souza (IFF/SVS, rosegalasm@gmail.com)
}

\begin{abstract}
Resumo: Estudos sobre anúncios publicitários que contemplam leituras multimodais têm contribuído para compreender as multiplicidades culturais e semióticas dos textos que circulam na sociedade contemporânea, bem como para a formação do cidadão crítico (MottaRoth e Hendges, 2010). No entanto, pouco se sabe como tais gêneros podem ser explorados em redes sociais educacionais. Com o objetivo de experienciar o ensino de línguas orientado por estudos de gêneros e multiletramentos por meio da Rede Social Educacional (REDU), neste trabalho reportamos um estudo com alunos em dois contextos distintos - na Universidade e em um Instituto Federal - para avaliação de um Material Didático Digital (MDD). Resultados apontam que o desenvolvimento de MDD na REDU possibilita a inserção em diversas práticas sociais e discursivas, porém requer adequações para o uso no ensino de línguas, levando em consideração os conhecimentos linguísticos, cultural, digital e social dos participantes. Por outro lado, isso caracteriza a necessidade urgente de trabalhos mais sistêmicos, por parte dos professores na escola, quanto ao processo de desconstrução e construção de gêneros no contexto escolar, principalmente explorando as multimodalidades e as multissemioses dos textos, instigando a formação de um leitor crítico e multiletrado para o engajamento em diferentes atividades sociais.
\end{abstract}

Palavras-chave: material didático digital, multiletramentos, gêneros discursivos.

\section{Exploring the Educational Social Network in language teaching: possibilities, genres and multiliteracies}

\begin{abstract}
Researches on advertisements that include multimodal readings have been helping to understand the cultural and semiotic texts multiplicities that circulate in contemporary society as well as to the formation of critical citizen (Motta - Roth and Hendges, 2010). However, little is known how such genres can be explored in educational social networks. In order to experience the language teaching guided by studies of genres and multiliteracies through Educational Social Network (REDU), in this paper we report a study with students in two different contexts - at the University and at a Federal Institute - for evaluating a Digital teaching material. Results indicate that the development of MDD in REDU enables the insertion into several social and discursive practices, but it requires adjustments for using it in the language teaching, considering the linguistic, cultural, digital and social knowledge of the participants. On the other hand, this work highlights the urgent need for more systemic work, by teachers in the school, as well as the construction and deconstruction of genres in the school context, particularly exploring the multimodalities and multissemioses of texts, inciting multiliteracies of critical readers engaged in different several social activities.
\end{abstract}

Keywords: digital teaching material, multiliteracies, discursive genres.

\section{Introdução}

Com a crescente evolução das Tecnologias de Informação e Comunicação (TIC) nas práticas docentes e o acesso aos conteúdos disponibilizados eletronicamente por meio de uma diversidade de canais, a construção de conhecimento do aluno tem sido potencializada, seja de modo autônomo ou colaborativo (MORAN, 2011) por meio de ferramentas digitais. Devido a isso, aprender e ensinar na contemporaneidade são processos que precisam ser repensados, pois é urgente explorar em sala de aula novos contextos de interação e de usos da linguagem que circulam na sociedade. 
Na última década, estudos na Linguística Aplicada orientados na perspectiva dos gêneros discursivos têm se preocupado em destacar a necessidade de promover o ensino a partir de contextos específicos de uso da linguagem, assim como por meio de atividades sociais e gêneros em que os participantes de uma determinada comunidade interagem para produzir linguagem (Meurer, 2005; Motta-Roth e Heberle, 2005). Embora haja grandes avanços teóricos nessa área de pesquisa, ainda parece necessário entender melhor como se realizam os processos de ensino e de aprendizagem da linguagem, quando esses ocorrem em contextos específicos de uso, tais como, os que emergem no contexto mediado por tecnologias (Reis, 2010).

Tendo por base esses pressupostos, o Projeto Laboratório de Ensino e Aprendizagem de Línguas Online (LabEOn) tem se preocupado em explorar contextos virtuais diversos de interação social na Internet, bem como elaborado e testado Materiais Didáticos Digitais (MDD) e recursos tecnológicos educacionais, encontrados gratuitamente na Internet, para o ensino de línguas, a fim de promover a fluência e o letramento digital dos participantes do projeto (Reis et al., 2012; Cecchin e Reis, 2013).

Neste artigo, reportamos um estudo realizado em 2013 no LabEOn, visando o desenvolvimento de multiletramentos pelo uso da Rede Social Educacional (REDU) e gêneros discursivos multimodais. Assim, na primeira seção, apresentamos uma breve abordagem sobre gêneros discursivos, multiletramentos e tecnologias na escola; na segunda, discutimos o uso de redes sociais educativas no ensino de línguas; na terceira, propomos a metodologia desta pesquisa; na quarta, analisamos e discutimos a plataforma em estudo, além do MDD proposto e, por fim, destacamos as considerações finais.

\section{Tecnologias na escola, gêneros discursivos e multiletramentos.}

Estudos recentes em Linguística Aplicada envolvendo gêneros discursivos e digitais, tais como: anúncios publicitários (Motta-Roth e Hendges, 2010); tiras em quadrinhos (Catto e Hendges, 2010); análise multimodal de imagens (Nascimento et al., 2011); anúncios de propagandas (Bezerra et al., 2010); podcast (Rosell-Aguilar, 2009; Reis et al., 2012); blogs (Caiado, 2007; Reis et al., 2008); bate-papo educacional (Araújo e Costa, 2007; Leal, 2007) têm contribuído com discussões sobre como explorar gêneros discursivos e digitais em sala de aula.

Na mesma direção, Meurer e Motta-Roth (2002) sugerem que é papel do professor orientar os alunos na compreensão de como ocorrem as diferentes manifestações da linguagem, ao possibilitar a discussão e análise de gêneros, uma vez que, de acordo com os autores, ao analisar gêneros deve-se focalizar sobre o que se fala, quem fala e como se fala em determinadas situações de uso da linguagem (Reis, 2010), já que falantes e escritores usam gêneros de diferentes maneiras com vistas a preencher certas funções sociais e alcançar certos objetivos, dentro de diferentes contextos sociais e culturais (Meurer, 2005).

Para Motta-Roth (2008, p. 247) gêneros são "eventos realizados discursivamente por elementos linguísticos em diferentes planos”. Portanto, gêneros "podem ser entendidos como linguagem culturalmente pertinente a uma dada situação, atravessada por discursos de ordens diversas”. Sendo assim, explorar gêneros no ensino pode ser uma maneira de promover multiletramentos tão essenciais na sociedade contemporânea. Para isso, é preciso fomentar novas propostas de como elaborar atividades didáticas que explorem gêneros e o uso de tecnologias em sala de aula (Xavier, 2009). 
Do mesmo modo, Motta-Roth e Nascimento (2009, p. 320) destacam que na "sociedade globalizada e multicultural, com sua multiplicidade de registros, discursos, canais de comunicação e modos de representação, os professores devem repensar o conceito de letramento". Assim, incluir atividades em sala de aula, que envolvam leitura multimodal, pode contribuir para os vários letramentos dos alunos, e para a construção dos significados culturais desses textos (Motta-Roth; Nascimento, 2009).

Estudos sobre multiletramentos na escola (Rojo e Moura, 2012) propõem que devemos levar em consideração os variados letramentos presentes nos diferentes contextos culturais, sociais ou profissionais, bem como a natureza das novas tecnologias de comunicação. Na mesma direção, Kalantzis e Cope (2008) sugerem que os significados são construídos, cada vez mais, pela multimodalidade, envolvendo interfaces com padrões visuais (cores, imagens), áudio, significação gestual e espacial.

Tendo como base os estudos do New London Group, Rojo (2012) destaca que os multiletramentos, por serem multi, devem atender a multiculturalidade da sociedade globalizada e a multimodalidade presente nessa sociedade. Para a autora, a multiplicidade cultural da população diz respeito à circulação de textos híbridos que exigem vários letramentos no contexto social, implicando "um processo de escolha pessoal e político” (Rojo, 2012, p. 13). Já a multiplicidade semiótica está relacionada aos mais variados recursos utilizados nos textos em circulação social, ou seja, a multimodalidade (ou a multissemiose) encontrada em forma impressa, em mídias audiovisuais ou digitais.

\subsection{Tecnologias na escola: Rede Social Educacional}

As redes sociais, favorecidas pela Web 2.0, passaram a ser motivo de estudos de pesquisadores preocupados com o uso desses recursos tecnológicos para o ensino. De acordo com Marteleto (2010, p. 28), as redes sociais "permitiram a construção de uma compreensão inovadora da sociedade, que ultrapassa os princípios tradicionais, nos quais o elo social é visto como algo que se estabelece em função dos papéis instituídos e das funções que lhes correspondem”. Nessa visão inovadora da sociedade, os usuários em rede se unem por interesses comuns, afinidades e anseios, interconectados no mundo globalizado, a fim de uma (re)significação social e cultural.

Na Internet, a expressão redes sociais "pode ser resultado do tipo de uso que os atores sociais fazem de suas ferramentas (os sites de redes sociais)" (Recuero, 2009, p. 92). Assim, caso os participantes sociais explorem tais espaços virtuais para a educação, surge uma nova categoria de rede, ou seja, as redes sociais educacionais. Essa categoria, segundo Umbelina (2012, p. 7) funciona "como uma rede social virtual comum, com a diferença de que são voltadas especificamente para a educação”.

Com isso, a conexão estabelecida nas redes educacionais entre professores, alunos, pais e escola favorece a comunicação e a interação entre os participantes desse contexto, pois é possível trocar experiências, compartilhar informações e contribuir em um espaço virtual seguro e fechado (Umbelina, 2012).

As redes sociais educativas funcionam também como ambientes virtuais de aprendizagem, ofertando recursos que auxiliam a elaboração de atividades, tarefas educativas, assim como o gerenciamento da interação dos alunos na própria plataforma. Para exemplificar algumas redes sociais educacionais, Umbelina (2012) destaca as seguintes: Eba - USP/SP (http://www.ebah.com.br/); Passei Direto - PUC/RJ (http://passeidireto.com/); Stoa - USP/SP (http://social.stoa.usp.br/); Edmodo - USA (https://www.edmodo.com/); REDU - UFPE (http://www.redu.com.br/). No entanto, a 
autora enfatiza que a REDU é a rede que mais se aproxima da realidade das escolas, tendo em vista as experiências relatadas em eventos de tecnologia na educação.

\section{Metodologia desta pesquisa}

Para realizar este estudo, optamos por uma pesquisa qualitativa do tipo estudo de caso, entendido por Lüdke e André (1986, p.17) como a mais apropriada quando o interesse do pesquisador é investigar uma situação singular, particular, em que "o caso é sempre bem delimitado, devendo ter seus contornos claramente definidos no desenvolver do estudo”. Portanto, neste estudo buscamos investigar o uso da plataforma REDU para propormos aulas de leitura que explorassem gêneros multimodais para a promoção dos multiletramentos de participantes envolvidos no projeto.

\subsection{Contexto da pesquisa e participantes}

Esta pesquisa faz parte das investigações em desenvolvimento no Projeto Laboratório de Ensino e Aprendizagem de Línguas Online (LabEOn), registrado na UFSM, pelo número 031720. Esse projeto tem como objetivos: investigar as práticas discursivas e sociais que se realizam na Internet (Reis, 2010), com vistas a implementar ações de ensino e de aprendizagem de LE por meio de ambientes virtuais e, também, elaborar Material Didático Digital (MDD) por meio de gêneros discursivos e digitais.

Os participantes deste estudo são sete alunos de Ensino Médio provenientes do Instituto Federal Farroupilha (IFF-SVS) e quatro alunos de graduação em Letras-Inglês, da UFSM. É oportuno salientar que os alunos voluntários eram do $1^{\circ}$ ano do Curso Técnico em Agropecuária, na modalidade de educação profissional técnica de nível médio integrado, no IFF-SVS, e apresentavam um nível baixo de letramento digital e acesso restrito às TIC. Os acadêmicos do Curso de Letras, estudantes do $4^{\circ}$ e $6^{\circ}$ semestres, possuíam nível médio de letramento digital e acesso amplo às tecnologias digitais.

\subsection{Objeto de estudo}

O MDD em investigação neste trabalho foi elaborado por professores em formação continuada, participantes do LabEOn e consta de uma proposta de aula de um curso online, ofertada na plataforma REDU, envolvendo aulas de leitura e produção textual, explorando gêneros discursivos e multimodais presentes no contexto social.

Para a produção do material didático, usamos o processo cíclico de MDD (Figura 1), proposto no Projeto LabEOn. Para isso, primeiramente, analisamos o perfil e interesses dos participantes do projeto, para após planejarmos e desenvolvermos os módulos do curso. Esses módulos em investigação foram denominados de: Leitura multimodal e de produção de anúncio publicitário e Multiletramentos: foco na produção de material didático. 


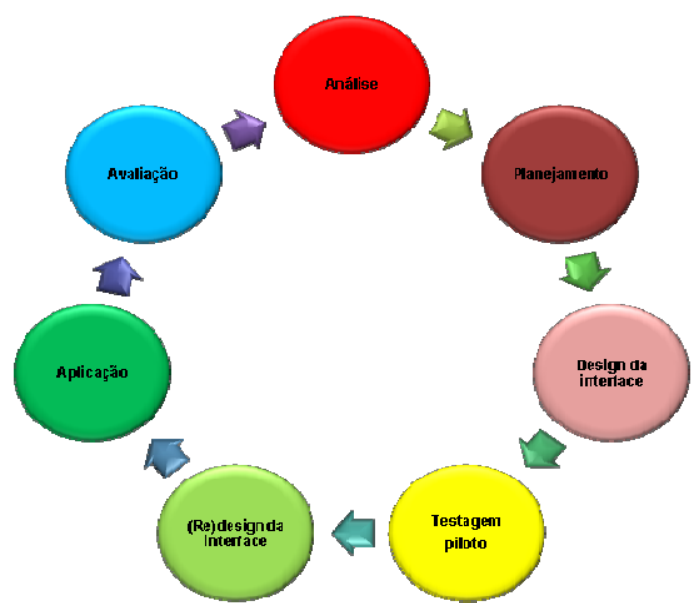

Figura 1 - Processo cíclico de elaboração de MDD proposto pelo LabEOn (ampliada de Reis et al, 2012)

As atividades do módulo Leitura multimodal e produção de anúncio publicitário apresentam dois propósitos básicos: o primeiro direcionado para a linguagem, integrando gênero discursivo e leitura multimodal presentes nas situações comunicativas que os participantes se envolvem, o segundo consiste na obtenção dos múltiplos letramentos necessários para o domínio tecnológico e seleção de materiais para a execução das atividades.

No módulo Multiletramentos, a proposta foi ofertar subsídios para uma reflexão sobre a produção de materiais didáticos que integre tecnologias educacionais e ensino de leitura por meio do gênero anúncio publicitário, bem como para desenvolver o letramento digital dos professores em formação inicial.

Na próxima etapa, realizamos a testagem do protótipo para possibilitar a avaliação do MDD pela equipe do Projeto LabEOn. Essa testagem foi realizada tanto com os alunos do Ensino Médio do IFF, Campus São Vicente do Sul - RS, quanto com os acadêmicos do Curso de Letras-Inglês, da UFSM.

O gênero discursivo em foco no MDD é o anúncio publicitário, visto que alguns autores consideram esse gênero uma rica fonte de informação cultural, por carregarem em seu texto marcas verbais e não verbais que complementam a produção do significado e a compreensão do texto (Motta-Roth e Hengdes, 2010).

\subsection{Instrumentos de coleta de dados}

Os instrumentos de coleta de dados utilizados foram a plataforma REDU, as produções dos estudantes e os questionários de avaliação aplicados aos professores em formação inicial, após a realização das atividades do módulo. A análise e a discussão dos dados obtidos encontram-se na próxima seção.

\section{Análise e discussão sobre a plataforma em estudo e o MDD proposto}

REDU é uma plataforma para ensino com tecnologia que permite ao professor, mesmo sem um nível de letramento digital avançado, postar atividades, empregando recursos, por meio de material para orientação, fundamentação e experiências didáticas, tais como: textos para leitura, interpretação, exercícios automatizados, posts instantâneos, vídeos. 
Para entendermos como está organizada a REDU, analisaremos a plataforma focando quatro recursos, que são: recursos de interação, recursos didáticos, recursos de gerenciamento das atividades e recursos de personalização.

Como recursos de interação, incluímos o mural, o espaço destinado à postagem ou inserção de comentários, a central de ajuda, a interação com outras redes sociais e, ainda, o chat. Desses recursos, destacamos que o chat apresenta certa restrição de uso, tendo em vista que não proporciona a opção de adicionar mais de um participante na mesma interação, o que poderia favorecer a retirada de dúvidas na execução das atividades. Por acreditamos que aprender a linguagem se dá pela interação social, evidenciamos que os recursos de interações na REDU não favorecem o compartilhamento de conhecimentos entre os participantes, pois limita a interação entre os alunos, favorecendo apenas o contato professor-aluno.

Para realizarmos os comentários e provermos respostas às atividades, no REDU, essas interações são realizadas no espaço denominado postagem de comentários, que possui funcionalidade semelhante a um fórum, porém sua capacidade é de incluir no máximo 800 caracteres, não permitindo a inserção de imagens e anexos, somente links.

Outra limitação apresentada pela REDU é a de não permitir que os alunos postem suas atividades na própria plataforma. Com isso, é necessário que o professor recorra a recursos como o e-mail, Google Drive, Dropbox, entre outros para envio de tarefas. Nessa situação, o aluno não se torna completamente ativo na produção do seu conhecimento por meio da REDU, e tem suas ações e atividades limitadas.

Os recursos didáticos encontrados na REDU nos proporcionam a organização de cursos e disciplinas em módulos sistematicamente organizados. Os conteúdos das disciplinas podem ser postados em vários formatos, por exemplo, em Pdf, Word, em Html, entre outros, possibilitando a inserção de links, imagens, vídeos, materiais de apoio e exercícios pré-estruturados. Essa organização oportuniza que o participante se sinta suficientemente orientado com relação às atividades que precisa desenvolver, ao mesmo tempo, em que proporciona segurança quanto à forma de realizá-las. Isso estimula o engajamento do estudante e sua continuidade na continuação da aprendizagem.

A plataforma permite a inserção de hiperlinks entre/ou nas atividades, bem como oferta a opção de solicitação de ajuda para a execução das tarefas, que poderá ser atendida pelo professor, tutor ou qualquer participante do curso.

Como recursos de gerenciamento das atividades, a REDU possibilita o acompanhamento por meio da visualização dos acessos dos estudantes, gerando um relatório de desempenho desses na execução dos exercícios propostos. Possui, também, ícones que indicam quem são os participantes online e, ainda, o percentual de atividades realizadas pelos alunos.

Concluindo a análise da REDU, apresentamos os recursos de personalização da plataforma, que consistem em: escolha do nome dos cursos, disciplinas e conteúdos, edição do perfil, configurações do ambiente e prazos para a realização das atividades. A opção de ligar e desligar luzes internas com o objetivo de destacar as tarefas é outro recurso disponível. A REDU dispõe, também, de mecanismo de busca que auxilia a localização por palavras-chave dos conteúdos ou de cursos existentes na plataforma.

\subsection{O MDD proposto para o ensino de língua inglesa usando a tecnologia REDU}

O MDD elaborado é composto de dois módulos (Leitura multimodal e produção de anúncio publicitário e Multiletramentos: foco na produção de material didático), sendo 
o primeiro aplicado apenas aos alunos do Ensino Médio e o segundo, Multiletramentos, direcionado aos professores em formação inicial.

O Módulo (1) Leitura multimodal e produção de anúncio publicitário viabiliza atividades de diagnóstico dos conhecimentos prévios dos estudantes sobre gêneros discursivos, apresentando textos pertencentes a diferentes gêneros, inclusive digitais, para que o participante identifique seu objetivo comunicativo, veículo e contexto de circulação.

Além dessas atividades, propomos uma leitura orientada do gênero anúncio publicitário (Figura 2), com a finalidade de apresentar uma atividade de desconstrução, seguindo os movimentos existentes nesse gênero discursivo, a partir da análise retórica de um anúncio publicitário proposta por Motta-Roth e Hendges (2010).
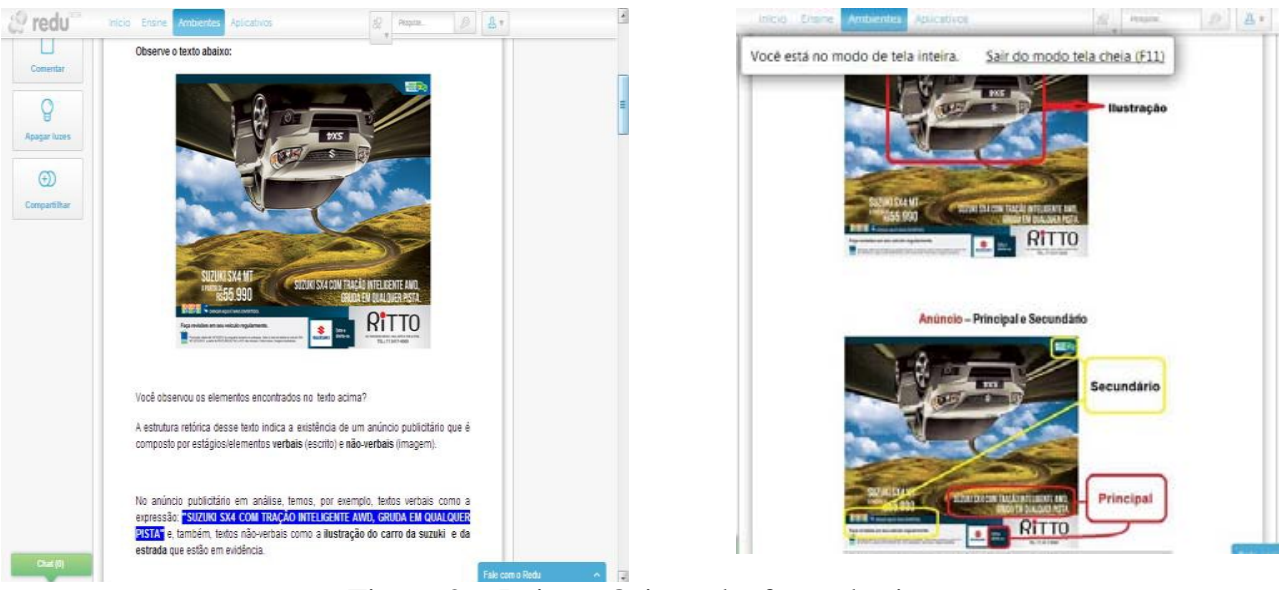

Figura 2 - Leitura Orientada, fonte das imagens

http://www.viamidia.com.br/site/category/campanhas/page/2/

Após praticarem os aspectos teóricos estudados na leitura orientada, os alunos acessam outro exemplar do mesmo gênero, estudando a língua inglesa no anúncio. Nesse momento, além dos conteúdos apresentados nessa atividade, buscamos propor tarefas que explorassem as funcionalidades da REDU, a partir do uso dos recursos comentar, pedir ajuda e chat com a finalidade de gerar interação e colaboração entre os participantes. A partir de atividades de leitura multimodal, os alunos do Ensino Médio desenvolveram a produção individual de um anúncio publicitário como tarefa final do módulo. A Figura 3 ilustra uma tarefa enviada por um aluno do Ensino Médio.

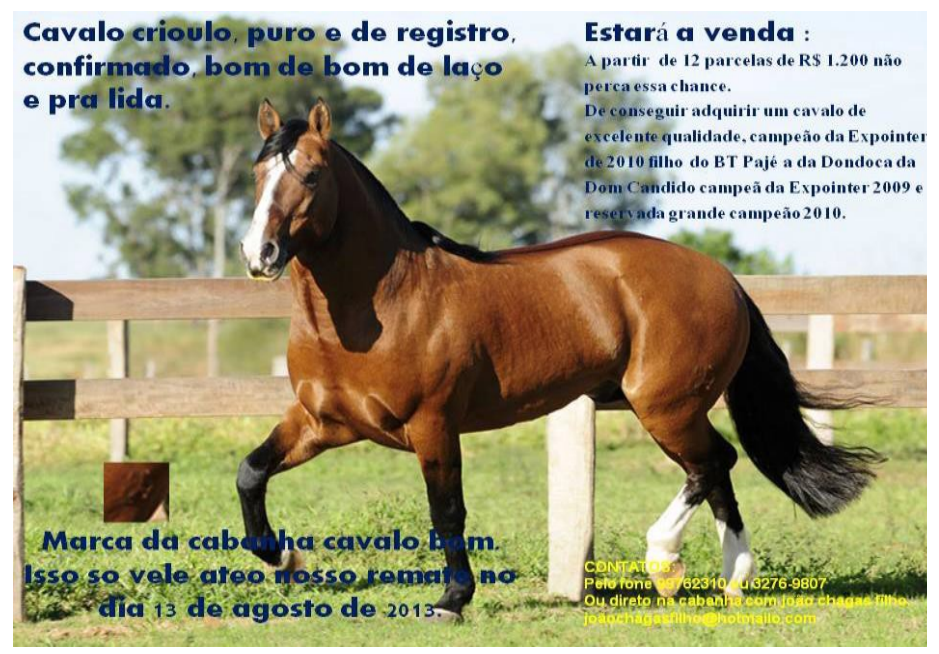

Figura 3 - Tarefa final do Módulo 
No Módulo Multiletramentos, elaborado para os professores em formação inicial, do Curso de Letras da UFSM, sugerimos que eles realizassem as mesmas tarefas propostas no Módulo 1 e, como produção final elaborassem uma nova atividade de leitura, utilizando o gênero anúncio publicitário, com atividades de linguagem que contemplassem explorar a multimodalidade e os recursos da REDU. A Figura 4 ilustra uma atividade elaborada por um aluno de Letras em formação inicial.

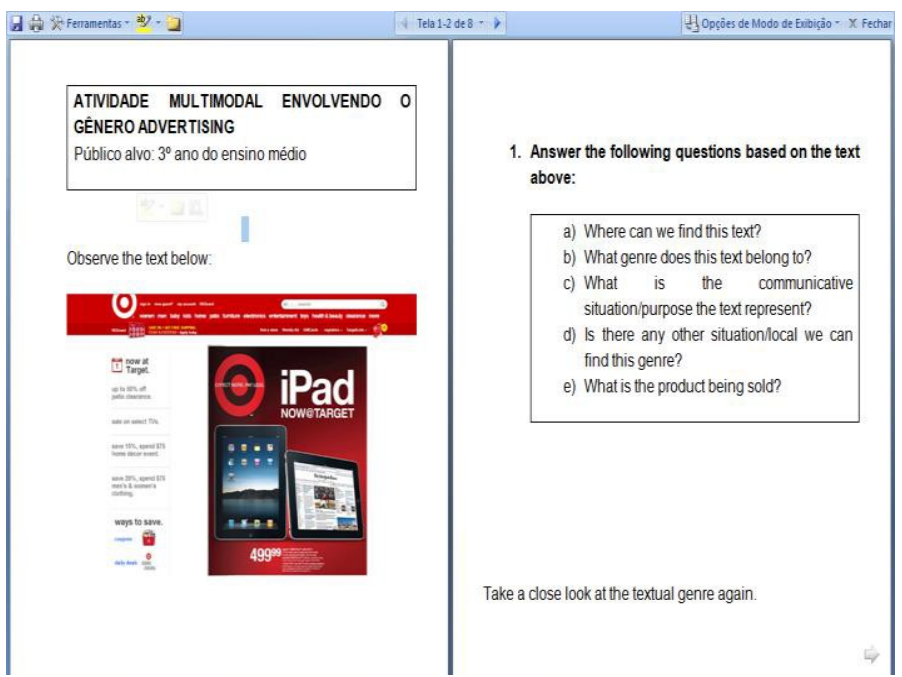

Figura 4 - Atividade dos alunos em formação inicial, fonte da imagem: http://www.target.com/

Ao elaborarem atividades, os alunos de formação inicial modificaram muito pouco o modelo de tarefa apresentada no Módulo 1, explorando em suas propostas de atividades os estágios verbais e não verbais, os termos integrantes obrigatórios e opcionais do anúncio publicitário, bem como os aspectos linguísticos do texto. Além da análise retórica, as atividades elaboradas pelos alunos de Letras exploraram a compreensão de vocabulários para melhor efetivação da leitura do texto, sem efetivamente explorarem os recursos da plataforma REDU.

O referido estudo evidenciou que as atividades propostas no Módulo 1 despertaram o interesse dos alunos do IFF quanto ao uso da REDU em sala de aula, embora os participantes tenham demonstrado dificuldades para a realização das tarefas, devido ao baixo nível de letramento linguístico e digital. Além disso, esse estudo apontou que a REDU poderia possibilitar maior interação entre usuários e o conteúdo, permitindo participação mais ativa e colaborativa dos alunos, principalmente para favorecer os processos de desconstrução e construção dos textos. Por outro lado, a plataforma REDU possibilita ao professor, mesmo com letramento mínimo, propor tarefas que motivem o aluno a se inserir no contexto digital e explorar as diferentes multissemioses e multimodalidades do meio virtual, ainda que seja de modo tímido.

Conforme avaliação realizada com os professores em formação inicial, por meio de questionários, na opinião deles a plataforma REDU é apropriada para uso com estudantes de Ensino Médio, haja vista que é uma rede social e estas fazem parte das atividades diárias dos jovens. Além de apresentar uma interface amigável, de fácil acesso mesmo para estudantes que não possuem letramento digital, os alunos em formação inicial sugeriram que a rede parece bastante atrativa e prática, por permitir o acompanhamento e controle das aulas e das atividades realizadas, além de possibilitar o contato direto com o tutor/professor por meio da ferramenta chat.

No que se refere ao material didático proposto para aulas de língua inglesa disponível na REDU, os acadêmicos consideraram apropriado ao Ensino Médio e as 
atividades bem estruturadas, dinâmicas, cativantes, interativas e desafiadoras, o que pode estimular o engajamento do aluno na realização das tarefas propostas. Para os professores em formação inicial a linguagem utilizada nas instruções das atividades foi avaliada como clara e coerente, possibilitando a compreensão das orientações, inclusive, por quem possua um nível baixo de letramento linguístico. Ainda, salientaram a importância das leituras e do material de apoio disponibilizado, pois, na opinião dos alunos de Letras, esses materiais esclarecem dúvidas e favorecem a continuidade da realização das tarefas.

\section{Considerações finais}

A experiência vivenciada pelos participantes, tanto pelos alunos do Ensino Médio quanto pelos do ensino superior, permitiu que avaliássemos que o MDD proposto precisa ser redesenhado para os diferentes públicos envolvidos, tendo em vista o grau de conhecimento, o nível cultural e social desses participantes.

Isso evidencia, também, a necessidade urgente de trabalhos mais sistêmicos, por parte dos professores no processo de desconstrução e construção de gêneros no contexto escolar, principalmente explorando diferentes gêneros discursivos, as multissemioses e a multimodalidade, de modo a instigar um leitor crítico em relação aos textos e os multiletramentos tão essenciais na sociedade contemporânea.

Os resultados obtidos neste trabalho não são conclusivos, no entanto, verificamos que além da plataforma REDU apresentar restrições de interação, as atividades propostas elaboradas pelos organizadores focalizaram preferencialmente a leitura do gênero em estudo, sem explorar uma quantidade suficiente de exemplares que possibilitasse aos alunos, com destreza, a produção independente ou colaborativa de um anúncio publicitário contendo todos os movimentos da análise retórica.

Ao realizar a atividade de produção independente, observamos que os participantes necessitavam de outros letramentos, tais como: linguístico, visual, digital que os possibilitassem melhor explorar recursos na produção de um anúncio, com relação ao design e à organização textual do gênero em estudo. Por outro lado, o desenvolvimento de material didático para língua inglesa por meio da REDU possibilita a inserção dos alunos em práticas sociais e discursivas que são mediatizadas por meio de gêneros discursivos e digitais, porém para que isso se concretize são necessárias implementações nos MDD propostos, a fim de que seu uso seja efetivo no ensino de línguas.

Essa constatação reforça a importância da testagem do MDD elaborados, o seu replanejamento, bem como nova aplicação e avaliação, para que o seu uso seja mais efetivo, atrativo, não gerando desmotivação do aluno ou abandono do curso, principalmente quando tais interações se efetivam na modalidade a distância.

Diante disso, novos módulos de MDD, envolvendo habilidades linguísticas, letramento digital, visual e gêneros discursivos presentes no contexto real dos alunos estão sendo planejados pelo LabEOn, como também estudos utilizando novos recursos que venham a ser disponibilizados pela REDU, tendo como foco a melhoria da eficiência do material didático para o contexto digital.

\section{Referências}

ARAÚJO, J. C.; COSTA, N. Momentos interativos de um chat aberto: a composição do gênero. In: ARAÚJO, J. C. (Org.). Internet \& ensino: novos gêneros, outros desafios. Rio de Janeiro: Lucerna. 2007. 21-34 p. 
BEZERRA, F. A. S.; NASCIMENTO, R. G.; HEBERLE, V. M. Análise multimodal de anúncios do programa “Na Mão Certa”. Rev. Letras, v.20, p.9-26, 2010.

CAIADO, R. V. R. Ortografia no gênero weblog: entre a escrita digital e a escrita escola. In: ARAÚJO, J. C. (Org.). Internet \& ensino: novos gêneros, outros desafios. Rio de Janeiro: Lucerna. 2007. 35-47 p.

CATTO, N. R.; HENDGES, G. R. Análise de gêneros multimodais com foco em tiras em quadrinho. Signum - Estudos de Linguagem, v.13, p.193-217, 2010.

CECCHIN, A. S.; REIS, S. C. Ensino de produção textual hipermidiática e interativa: um estudo de caso. Revista Intersecções, v.6, n.2, p.47-67, 2013.

KALANTZIS, M.; COPE, C. Language Education and Multiliteracies. In: MAY, S.; HORNBERGER, N. H. (Org.). Encyclopedia of Language and Education. 2 ed. Springer. 2008. 195-211 p.

LEAL, V. P. L. V. O chat quando não é chato: o papel da mediação pedagógica em chats educacionais. In: ARAÚJO, J. C. (Org.). Internet \& ensino: novos gêneros, outros desafios. Rio de Janeiro: Lucerna. 2007. 48-63 p.

LUDKE, M \& ANDRÉ, M.E.D.A. Pesquisa em educação: abordagens qualitativas. São Paulo: Editora Pedagógica e Universitária, 1986.

MARTELETO, R. M. Redes sociais, mediação e apropriação de informações: situando campos, objetos e conceitos na pesquisa em Ciência da Informação. Pesq. Bras. Ciência da Informação, Brasília, v.3, n.1, p.27-46, jan./dez. 2010.

MEURER, J. L; MOTTA-ROTH, D. Introdução. In: MEURER, J. L; MOTTA-ROTH, D. (Org.). Gêneros textuais e práticas discursivas: subsídios para o ensino da linguagem. Bauru, SP: EDUSC. 2002. 9-14 p.

MEURER, J. L. Gêneros textuais na análise crítica de Fairclough. In: MEURER, J.L; BONINI, A.; MOTTA-ROTH, D. (Org.). Gêneros: teorias, métodos, debates. São Paulo: Parábola editorial. 2005. 81-106 p.

MORAN, J. M. A educação que desejamos: novos desafios e como chegar lá. 5 ed. Campinas: Papirus, 2011.

MOTTA-ROTH, D.; HEBERLE, V. O conceito de estrutura potencial do gênero de Ruqaya Hasan. In: MEURER, M.; BONINI, A.; MOTTA-ROTH, D. Gêneros, teorias, métodos e debates. 1 ed. São Paulo: Parábola Editorial. 2005. 12-28 p.

MOTTA-ROTH, D. Para ligar a teoria à prática: roteiro de perguntas para orientar a leitura/análise crítica de gênero. In: MOTTA-ROTH, D.; CABANAS, T.; HENDGES, G. R. (Org.). Análise de textos e de discursos: relações entre teorias e práticas. 2.ed. Santa Maria: PPGL - Editores. 2008. 
MOTTA-ROTH, D.; NASCIMENTO, F. S. Transitivity in visual Grammar: concepts and applications. Linguagem \& Ensino, v.12, n.2, p.319-349, jul./dez. 2009.

MOTTA-ROTH, D; HENDGES, G. R. Explorando modalidades retóricas sob a perspectiva da multimodalidade. Rev. Letras, v.20, n.40, p.43-66, jan./jun. 2010.

NASCIMENTO, R. G.; BEZERRA, F. A. S.; HEBERLE, V. M. Multiletramentos: iniciação à análise de imagens. Linguagem \& Ensino, v.14, n.2, p.529-552, jul./dez. 2011.

RECUERO, R. Redes Sociais na Internet. Porto Alegre: Sulina. 2009. 191 p.

REIS, S. C.; MOREIRA, T. M.; TURA, D. L. O uso de blogs na aprendizagem da língua inglesa: uma experiência na escola pública. Revista Tecnologias na Educação, v.1, p.1-11, 2008.

REIS, S. C. Do discurso à prática: textualização de pesquisas sobre ensino de inglês mediado por computador. Santa Maria: PPGL/UFSM, 2010. 242 p. Tese de Doutorado em Estudos Linguísticos.

REIS, S. C.; GOMES, A. F.; LINCK, A. J. M. Uso de podcast no ensino de língua inglesa: um estudo de caso. Revista Escrita, v.15, p.1-18, 2012.

ROSELL-AGUILAR, F. Podcasting for language learning: re-examining the potential. In: LOMICKA, L.; LORD, G. (Org.). The next generation: social networking and online collaboration in foreign language learning. 8 ed. Texas, USA: Editora CALICO. 2009. 13-34 p.

ROJO, R. Pedagogia dos multiletramentos: diversidade cultural e de linguagem na escola. In: ROJO, R.; MOURA, E. (Org.). Multiletramentos na escola. São Paulo: Parábola Editorial. 2012. 11-31 p.

ROJO, R.; MOURA, E. Multiletramentos na escola. São Paulo: Parábola Editorial, 2012. 264 p.

UMBELINA, V. Redes sociais: aliadas ou vilãs da educação? Hipertextus Revista Digital, n.9, dez. 2012.

XAVIER, A. C A era do hipertexto: linguagem e tecnologias. 1 ed. Recife: Editora Universitária da UFPE. 2009. 227 p. 